Significant minor events reported by 78 doctors and physiotherapists in 31822 acupuncture consultations

Event

Administration problems:

Needle lost or forgotten

Patient forgotten in treatment room 2

Application site problems:

Cellulitis after treatment of oedematous leg ${ }^{\star}$

Blister following moxibustion

\begin{tabular}{ll} 
Needle allergy & 2 \\
\hline Needle site pain* (one case lasted 2 weeks) & 3
\end{tabular}

Cardiovascular problems:

Fainting 6

Gastrointestinal problems:

Nauseat 2

Vomiting

General problems:

Patient fell asleep during treatment

Drowsiness ${ }^{*}$ (one case lasted 1 day; one case lasted 1 week

Disorientation (one case lasted 1 hour; one case lasted 1 day)

Lethargy*

Neurological and psychiatric problems:

Anxiety and panic† (one episode lasted 60 hours) 2

Euphoria

Headache for 3 days

Hyperaesthesiae with numbness for 3 days $^{\star}$

Seizure shortly after insertion of needles (probably reflex anoxic) ${ }^{\star}$

Slurred speech

Exacerbation of symptoms:

Back pain, fibromyalgia, ${ }^{*}$ shoulder pain, ${ }^{*}$ vomiting, ${ }^{*}$ migraine ${ }^{\star}$

*Event led to reduction in daily activities in one patient.

tEvent led to reduction in daily activities in two patients.

significant. These event rates are per consultation, and they do not give the risk per individual patient.

Demographic data suggest that the acupuncturist volunteers were reasonably representative of the mem- bers of the two societies, but over-reporting and underreporting are inherently possible in such studies. High individual rates may be due to a low personal threshold for reporting, or they may indicate the need for further training of the acupuncturist. Some avoidable adverse events occurred, and acupuncturists might consider modifying their practice to reduce the incidence of such events.

We thank members of the British Medical Acupuncture Society and the Acupuncture Association of Chartered Physiotherapists for collecting data, Mike Fitter and Hugh MacPherson for advice in designing the questionnaire, and Val Hopwood for help in recruiting volunteers.

Contributors: EE, SH, and AW planned the study, which was supervised by AW. The data were collected by members of the British Medical Acupuncture Society and the Acupuncture Association of Chartered Physiotherapists. The results were collated by $\mathrm{AW}$, and $\mathrm{AH}$ performed the statistical analysis. The final report was written by $\mathrm{AW}, \mathrm{SH}, \mathrm{AH}$, and EE. AW and EE will act as guarantors.

Funding: The posts of $\mathrm{AW}$ and $\mathrm{EE}$ are funded by the Maurice Laing Foundation.

Competing interests: AW has received fees for lecturing at scientific and educational meetings arranged by the British Medical Acupuncture Society and the Acupuncture Association of Chartered Physiotherapists. SH has received fees for lecturing and for acting as editor of the professional journal of the British Medical Acupuncture Society, Acupuncture in Medicine.

1 Ernst E, White A. Life-threatening adverse reactions after acupuncture? A systematic review. Pain 1997;71:123-6.

2 White AR, Hayhoe S, Ernst E. Survey of adverse events following acupuncture. Acupunct Med 1997;15:67-70.

3 Edwards RI, Aronson JK. Adverse drug reactions: definitions, diagnosis, and management. Lancet 2000;356:1255-9.

4 Eypasch E, Lefering R, Kum CK, Troidl H. Probability of adverse events that have not yet occurred: a statistical reminder. BMJ 1995;311:619-20.

5 British Medical Association Ethics. Medical ethics today. Its practice and philosophy. London: BMA Professional Division Publications, 1993

(Accepted 17 May 2001)

\title{
The York acupuncture safety study: prospective survey of 34000 treatments by traditional acupuncturists
}

\author{
Hugh MacPherson, Kate Thomas, Stephen Walters, Mike Fitter
}

See Editorial by

Vincent and $\mathrm{p} 485$

Foundation for Traditional Chinese Medicine, York YO24 4EY

Hugh MacPherson research director

Mike Fitter

research consultant

continued over

BMJ 2001;323:486-7
Recent reports have highlighted the importance of having good evidence on the safety of acupuncture. ${ }^{12}$ Sound evidence on the risks associated with acupuncture is, however, scarce. ${ }^{3}$ Our primary aim, therefore, was to describe the type and frequency of adverse events after acupuncture. A secondary aim was to examine mild transient reactions associated with acupuncture, some of which may indicate a positive response to treatment.

\section{Participants, methods, and results}

The study involved a prospective postal audit of treatments undertaken during a four week period in 2000. All 1848 professional acupuncturists who were members of the British Acupuncture Council and were practising in the United Kingdom were invited to record details of adverse events and mild transient reactions after treatment. Standardised self report forms were used. Participating practitioners also provided information on themselves, including age, sex, length of training, and years of practice. To have a $95 \%$ probability that no serious event occurs in $n$ treatments, a survey sample size needs to be three times $n{ }^{4}$ On this basis, a sample of 30000 treatments was sought. Piloting indicated that a four week period was needed.

A total of 574 practitioners participated, $31 \%$ of the total population. The mean age of participants was 44.8 years (range $23-79$ years), $65 \%$ were female, and $62 \%$ had been practising acupuncture for more than five years. Information on sex, training college, and length of practice was available from the British Acupuncture Council's database. Participants were sufficiently representative of the population of practitioners for a re-weighting of the primary data to be unnecessary. Participating practitioners reported on 34407 treatments. 
Details of 43 minor adverse events associated with 34407 acupuncture treatments, all reported as "significant" by practitioners

\begin{tabular}{|c|c|c|}
\hline Minor adverse events & No of occurrences & Descriptions \\
\hline $\begin{array}{l}\text { Severe nausea, actual fainting, severe } \\
\text { dizziness, heavy sweating, and vomiting }\end{array}$ & 12 & $\begin{array}{l}5 \text { cases of severe nausea ( } 2 \text { with feeling faint, sweating, and dizziness; } 1 \text { started next day } \\
\text { and lasted several days; } 1 \text { started } 4 \text { days later with angina and nose bleeds); } 4 \text { fainted ( } 2 \\
\text { with nausea and dizziness); } 1 \text { severe dizziness and feeling faint; } 1 \text { heavy sweating and } \\
\text { slight needle shock; } 1 \text { vomiting after treatment }\end{array}$ \\
\hline $\begin{array}{l}\text { Unexpected, severe, and prolonged } \\
\text { aggravation of existing symptoms }\end{array}$ & 7 & $\begin{array}{l}1 \text { difficulty walking the next day because of stiff, painful legs; } 1 \text { increase in shoulder pain } \\
\text { for } 20 \text { minutes; } 1 \text { neck and shoulder pain increase for } 1 \text { week; } 1 \text { morning sickness } \\
\text { worsened; } 1 \text { diarrhoea in patient with colitis; } 1 \text { constipation in patient with irritable bowel; } \\
1 \text { temporary aggravation of neck pain }\end{array}$ \\
\hline $\begin{array}{l}\text { Prolonged and unacceptable pain and } \\
\text { bruising }\end{array}$ & 5 & 3 local pain at site of needling; 2 heavy bruising \\
\hline Psychological and emotional reactions & 4 & $\begin{array}{l}1 \text { emotional outburst and anger at practitioner; } 1 \text { feeling of panic with sensation of heat } \\
\text { and sweatiness; } 1 \text { intense emotional release, feeling manic, relaxed, rage, and confusion; } 1 \\
\text { depression with anxiety }\end{array}$ \\
\hline Avoidable errors & 3 & 2 forgotten needles; 1 moxibustion burns at 2 points \\
\hline Miscellaneous symptoms & 10 & $\begin{array}{l}1 \text { haematuria next day; } 1 \text { headache next day; } 1 \text { unwell, tired, sore throat, breathless, and } \\
\text { achy; } 1 \text { knee went weak and patient could not stand on it; } 1 \text { very tired next day; } 1 \text { felt sick } \\
\text { and exhausted; } 1 \text { severe drowsiness; } 1 \text { tiredness next day with } 10 \text { hours of diarrhoea; } 1 \\
\text { rash after taking herbs; } 1 \text { rash developed on abdomen a few days after treatment }\end{array}$ \\
\hline Unspecified & 2 & \\
\hline
\end{tabular}

Practitioners were asked to give details of any adverse events they considered to be "significant," including any event that was "unusual, novel, dangerous, significantly inconvenient, or requiring further information." There were no reports of serious adverse events, defined as events requiring hospital admission, leading to permanent disability, or resulting in death $(95 \%$ confidence interval 0 to 1.1 per 10000 treatments). Practitioners did, however, report 43 minor adverse events, a rate of 1.3 (0.9 to 1.7$)$ per 1000 treatments. The most common events were severe nausea and fainting (table). Three avoidable events-two patients had needles left in, and one patient had moxibustion burns to the skin-were caused by practitioners' errors.

Participating practitioners recorded 10920 mild transient reactions occurring in 5136 treatments, 15\% $(14.6 \%$ to $15.3 \%)$ of the 34407 total. Some local reactions at the site of needling were reported-mild bruising in $587(1.7 \%)$ cases, pain in $422(1.2 \%)$ cases, and bleeding in $126(0.4 \%)$ cases. Patients experienced an aggravation of existing symptoms after $966(2.8 \%)$ treatments, $830(86 \%)$ of which were followed by an improvement, possibly indicating a positive "healing crisis." The most commonly reported mild transient reactions were "feeling relaxed" in $4098(11.9 \%)$ cases and "feeling energised" in $2267(6.6 \%)$ cases, symptoms that often indicate an encouraging response to treatment. ${ }^{3}$

\section{Comment}

In this prospective survey, no serious adverse events were reported after 34407 acupuncture treatments. This is consistent, with $95 \%$ confidence, with an underlying serious adverse event rate of between 0 and 1.1 per 10000 treatments. This conclusion was based on data collected over a four week period by one in three of the members of the British Acupuncture Council. Even given the potential bias of self reporting, this is important evidence on public health and safety as professional acupuncturists deliver approximately two million treatments per year in the United Kingdom. Comparison of this adverse event rate for acupuncture with those of drugs routinely prescribed in primary care suggests that acupuncture is a relatively safe form of treatment. ${ }^{5}$ Further research measuring patients' experience of adverse events is merited.
Contributors: HMacP initiated the project, coordinated the study, and is the guarantor. KT and MF contributed to the study design, interpretation of results, and drafting of the manuscript SW analysed the data and assisted with the interpretation of results. The study was adapted from a survey design developed by Adrian White and colleagues. Alan Bensoussan, Stephen Birch, Alan Breen, Roy Carr-Hill, and Adrian White provided

Funding: The study was supported by a grant from the British Acupuncture Council.

Competing interests: None declared.

1 British Medical Association Board of Science and Education. Acupuncture: efficacy, safety and practice. London: Harwood Academic Publishers, 2000.

2 House of Lords. Complementary and alternative medicine. London: Stationery Office, 2000. (Report of the Select Committee on Science and Technology.)

3 MacPherson H. How safe is acupuncture? Developing the evidence on risk. J Alternative Complementary Med 1999;5:223-4

4 Eypasch E, Lefering R, Kum CK, Toidl H. Probability of adverse events that have not yet occurred: a statistical reminder. BMJ 1995;311:619-20.

5 Tranmer MR, Moore RA, Reynolds DJM, McQuay HJ. Quantitative estimation of rare adverse events, which follow a biological progression: a new model applied to chronic NSAID use. Pain 2000;85:169-82.

(Accepted 23 May 2001)

\section{Corrections and clarifications}

Systematic reviews of evaluations of diagnostic and screening tests

In this article by Jonathan J Deeks in the series "Systematic reviews in health care" (21 July, pp 157-62), several errors appeared in figure 2 . The numerators for specificity (right hand panel) should have been labelled as false positives [not true negatives]. The sensitivity point estimates for Nasri(b)and Taviani should be 1.0, and the specificity point estimate for Goldstein should be 0.41 [not 0.6]. We apologise for introducing the errors in the positioning of these points.

This Week in the BMJ

Although in the text of the summary of Lam and colleagues' article about smoking related deaths in China (This Week in the BMJ, 18 August) we acknowledged that Hong Kong is now part of China, we failed to publish a title that reflected this. We should have said "mainland China" [not just China].

Why a 1940s medical committee should not be forgotten We wrongly described Geoff Watts, the author of this news article (18 August, p 360), as the presenter of Medicine Now; this radio programme is of course no longer broadcast. Geoff Watts now presents the Radio 4 science programme Leading Edge. valuable comments on a draft protocol.
Medical Care Research Unit, University of Sheffield, Sheffield

S1 4DA

Kate Thomas

deputy director

Sheffield Health Economics Group, School of Health and Related Research, University of Sheffield

Stephen Walters lecturer in medical statistics

Correspondence to: $\mathrm{H}$ MacPherson hugh@ftcm.org.uk 